\title{
The Effects of Teaching Satisfaction on Teacher Motivation in Islamic Private Schools in Pattani Province, Thailand
}

\author{
Yahui Wang \\ Graducate School, Prince of Songkhla University, Pattain, Thailand
}

Email address:

muhe0129@gmail.com, abu0129@163.com

To cite this article:

Yahui Wang. The Effects of Teaching Satisfaction on Teacher Motivation in Islamic Private Schools in Pattani Province, Thailand. International Journal of Secondary Education. Vol. 5, No. 3, 2017, pp. 37-41. doi: 10.11648/j.ijsedu.20170503.12

Received: March 31, 2017; Accepted: April 19, 2017; Published: April 21, 2017

\begin{abstract}
The purpose of this research was to explore the relationship between teacher motivation and teaching satisfaction in Islamic Private schools in Pattani, Thailand. This study used questionnaire to collect data from 5 target schools with 212 teachers. The test of significance for multiple regression analysis was primarily performed at the probability level of $p<0.05$. Teacher motivation was positively and moderately related to the all five dimensions of teaching satisfaction, namely, personal teaching satisfaction, teaching satisfaction with pay, teaching satisfaction with school polices, teaching satisfaction with interpersonal relations and teaching satisfaction with career development. The results for multiple regression revealed that three out of five predictors of teaching satisfaction were positively statistically with teacher motivation across samples, namely, personal teaching satisfaction, teaching satisfaction with pay and teaching satisfaction with career development. The best predictor was personal teaching satisfaction. The recommendation for this study was school leaders and principals should take actions or strategies to increase teachers' motivation and satisfaction level to improve their work with more salary and support more school facilities. The significant relationship showed that the way to motivated teachers is to satisfied them in their personal demands, the pay and increase more professional training.
\end{abstract}

Keywords: Private Schools, Teacher Motivation, Teaching Satisfaction

\section{Introduction}

Education plays a very important role in all over the human's history while quality is the heart of education and this is what teachers and educators have to make efforts to ensure students have gotten what they need, so that how teachers teach and encourage them to teach with satisfaction and motivation is the key strategy. There is general agreement that motivated teachers are crucial to quality education, for example, The Oxfam Education Report by Watkins [1], cites that "motivated teachers" as one of the main elements associated with quality education. In the words of Vanbaren [2], teacher motivation is a process used to encourage and inspire teachers to perform their jobs thoroughly and well.

As educational quality attainment is greatly reliant on teachers who play a direct and major role in translating the curriculum into the classrooms or schools. And how teachers perform and behave in relation to their teaching are very much influenced by their inner driving force which somehow reflected through their levels of motivation and satisfaction with their jobs and schools. Good teaching behaviors or good acts showed by teachers can safely be assumed to be the results of their positive feeling and strong motive. Therefore, a study of the relationship between teacher motivation and teaching satisfaction is significant in the way to understand why teachers act the way they do.

The relevance of job satisfaction and motivation are very crucial to the long-term growth and development of any educational system around the world. When teachers are not satisfied with their job or they have no motivation to work, they are likely not showing a good performance [3]. Motivation is such a factor that exerts a driving force on their actions and work. A highly motivated teacher helps in achieving the school targets. Teaching satisfaction as a pleasurable or positive emotional state rustling teachers' perceptions of how well their job provides things that are viewed as important, which means, when they are not pleased by reward or the polices or any other factors they thought are important, they may show negative attitude and behaviors. [4]

The purpose of this study was to explore the relationship 
between teacher motivation and teaching satisfaction in Islamic private schools in Patinni, Thailand, to examine whether teacher motivation has a significant relationship with teaching satisfaction in the context of Islamic private schools. Further, the study was specifically designed to test the predictors of teacher motivation while teaching satisfaction variables as the independent variables and teacher motivation as the dependent variables.

To a large extent, this study is built on the theoretical frameworks of scholars like Herzberg, Mausner \& Snyderman [5], Convey and Maslow. [6] The questionnaire developed and used to gather data for this study adopted from this similar works on motivation and teaching satisfaction by authors like Convey, Herzberg, Mausner and Snyderman, Ifinedo [7] and many others.

\section{Research Method}

A quantitative approach using a survey method in this study aimed to collect data on the two main variables, namely, teacher motivation and teaching satisfaction. A multiple regression study was analyzed to answer the research question (what is the relationship between teacher motivation and what are the predictors (teaching satisfaction) of teacher motivation in Islamic private schools in Pattani, Thailand?)

\section{Results of the Study}

\subsection{Result of Correlation}

Correlation was measured to explore the degree of relationship between teacher motivation and teaching satisfaction. This correlation may have showed as strong, moderate, or low and the orientation of the relationship could be positive or negative. This result of correlation can be observed from visual inspection of the scatterplot graph or sample Person Product-Moment Correlation Coefficients, represented. The value of this ranges which between -1 to +1 will be index of the degree of closeness of the sample scatterplot to a straight line, it shows with the singe of demonstrating positive or negative linear relationship. The result of the correlation analysis yielded significant relationship between teachers' motivation and their teaching satisfaction. The result of the correlation analysis was presented in table 1, describes correlations between the teacher motivation and teaching satisfaction.

The correlation analysis using the Statistical Package for the Social Sciences (SPSS) computer revealed significant correlations between teacher motivation with teaching satisfaction in all dimensions, namely with personal teaching satisfaction $(\mathrm{r}=.63)$, teaching satisfaction with interpersonal relations $(\mathrm{r}=.53)$, teaching satisfaction with school polices $(\mathrm{r}=.49)$, teaching satisfaction with pay $(\mathrm{r}=.48)$ and teaching satisfaction with career development $(\mathrm{r}=.51)$.

The research demographic data showed that a total of 212 teachers completed the survey, of these, 141 (66.5\%) were female teachers and $71(33.5 \%)$ were male teachers. Half of them with $108(50.9 \%)$ were teachers whose age between 26-35 years old, $26(12.3 \%)$ of them were teachers whose age between 18-25 years old, 38 (17.9\%) of them were teachers whose age between $36-45$ years old, $30(14.2 \%)$ of them were teachers whose age between 46-55 years old, only $10(4.7 \%)$ of them are whose age were above 55 years old. A total of 198 teachers $(93.4 \%)$ hold bachelors as their highest degree, only 5 $(2.4 \%)$ of them had master degree and there were no teachers with Ph.D. degree. $9(4.2 \%)$ teachers of them hold other degree which include college certificate and other degree. The majority of teachers hold Bachelor degree, this might because of the nature of their profession requires bachelors as the basic standard.

A total of $208(98.1 \%)$ teachers were Muslims and only 4 $(1.9 \%)$ of them were Buddhist. As for teaching experiences, $17(8 \%)$ teachers who have teaching experiences less than 2 years, $71(33.5 \%)$ reported to have teaching experiences between 2 and 5 years, and $55(25.9 \%)$ reported between 6 and 10 years teaching, $26(12.3 \%)$ reported between 11 and 15 years, while $43(20.3 \%)$ reported more than 15 years teaching experiences.

Table 1. Correlations between Teacher Motivation and Teaching Satisfaction.

\begin{tabular}{ll}
\hline Teaching Satisfaction & Teacher motivation \\
\hline -Personal teaching satisfaction & $.63^{* *}$ \\
-Teaching Satisfaction with pay & $.48^{* *}$ \\
-Teaching Satisfaction with interpersonal relations & $.53^{* *}$ \\
-Teaching Satisfaction with school polices & $.49^{* *}$ \\
-Teaching Satisfaction with career development & $.51^{* *}$ \\
\hline
\end{tabular}

** Correlation is significant at 0.01 level

From the table 1 it can be seen that teacher motivation was significantly correlated with five dimensions of teaching satisfaction, namely personal teaching satisfaction $(\mathrm{r}=.63)$, teaching satisfaction with pay $(\mathrm{r}=.48)$, teaching satisfaction with interpersonal relations $(\mathrm{r}=.53)$, teaching satisfaction with school polices $(\mathrm{r}=.49)$, and teaching satisfaction with career development $(\mathrm{r}=.51)$. This meant that there was significant positive relationship between teacher motivation and the five teaching satisfaction dimensions (i.e., personal teaching satisfaction, pay, interpersonal relations, school polices, career development). As each dimension of teaching satisfaction showed marked improvement and increased frequency, there will be an increase in teacher motivation.

Moreover, according to the study, highest correlation is observed between teacher motivation and personal teaching satisfaction $(\mathrm{r}=0.63)$ suggesting that when teachers are satisfied with their job, it provides a strong driving force to accomplish ongoing and future work assignments and tasks.

\subsection{Result of Regression}

The regression analysis appraising the relies upon certain assumptions about the data used during the analysis. Aims to determine if the use of regression analysis on the data is justifiable, there were four fundamental regression assumptions techniques explored, which includes, normality of the error term distribution, linearity of the variables measured, constant variance of the error terms constant variance and independence of error terms. It may lead to 
incorrect estimation from violation of these assumptions, at the same time the validity of many statistical results, conclusions, and assertions if left questionable. The result was presented in table 2 .

A closed examination of the regression results reveals that $52 \%(\mathrm{R} 2=.52)$ of the observed variability in teacher motivation is explained by the five mentioned predictors. The adjusted R2 was .51, with an estimated standard error of .27. The overall strength of the model as depicted by the ANOVA table was statistically significant at the .05 level; $F(5,206)=$ 45.31, $\mathrm{P}<0.05, \mathrm{MSE}=.07$. Therefore, there must be at least one of the population regression coefficients presents.

Of the five predictors, personal teaching satisfaction, teaching satisfaction with pay and teaching satisfaction with career development were positively and significantly related to teacher motivation. Though teaching satisfaction with interpersonal relations and teaching satisfaction with school policies was significantly related to teacher motivation in the previous results, the present analysis yields an insignificant relationship between these two variables. Thus, three out of the five were statistically significant predictors of teacher motivation. The most significant predictor of teacher motivation was personal teaching satisfaction.

Using the generated coefficient, the estimated regression equation can be written as follows:

(1) $\hat{Y}=1.20+.34($ TSG) $+.09($ TSPAY $)+.12($ TSCD $)$

Whereby;

PTS = Personal Teaching Satisfaction

TSPAY $=$ Teaching Satisfaction with Pay, and

TSCD = Teaching Satisfaction with Career Development

According to the result, personal teaching satisfaction was the best predictor of teacher motivation as depicted by Beta $=37, \mathrm{t}=5.57, \mathrm{p}<0.05$; a unit change of teaching satisfaction in general is accompanied by .34 unit change in teacher motivation, controlling for other independent variables. The second significant predictor of teacher motivation in sequence was teaching satisfaction with pay (Beta=.19, $\mathrm{t}=3.34, \mathrm{p}<0.05$ ). The regression coefficient indicated that predicted teacher motivation increased an estimation of .09 units with one unit increasing in teaching stratification with pay, when the other variables are constant. The last important predictor in the model was teaching satisfaction with career development (Beta $=.19, \mathrm{t}=3.14$, $\mathrm{p}<0.05)$. the coefficient signifies that predicted teacher motivation increase by .12 units for an increase of 1 in the value of teaching satisfaction with career development.

To assess multicollinearity, the study uses tolerance valued and VIF, which build in the regression of each independent variable on all the others. A close examination on both the tolerance value and VIF provides evidence that the effect of multicollinearity was not a threat to the analysis.

It is important to note some limitations of this study. First, the samples used for this study are full time teachers in Islamic private schools in Pattani, one cannot generalize findings to other southern Thailand provinces (Satun, Songkhla, Yala and Narathiwat). Future researchers may focus on the limitations and work improving the generality of the results. Second, the study employed the quantitative research method only, therefore, a future research may employs mixed methods (i.e. combination of the quantitative and qualitative research methods) which will be more helpful. Third, this study was limited itself to teachers who are working in private secondary schools in Pattani, therefore, there is a need to conduct a comparative study on teacher motivation and teaching satisfaction among teachers working in private and public secondary schools in Pattani. The sample for the study should be increased to involve more teachers from private and public secondary schools in order to get rich data from different context and cultures.

Table 2. Regression Coefficients, Confidence Intervals, Collinearity Statistics ( $n=212)$.

\begin{tabular}{|c|c|c|c|c|c|c|c|c|c|c|}
\hline \multirow[b]{2}{*}{ Model } & \multirow[b]{2}{*}{ M } & \multirow[b]{2}{*}{ S.D } & \multirow[b]{2}{*}{ B } & \multirow[b]{2}{*}{ Std. E } & \multirow[b]{2}{*}{ Beta } & \multirow[b]{2}{*}{$\mathbf{t}$} & \multicolumn{2}{|c|}{$95 \% \mathrm{CI}$} & \multicolumn{2}{|c|}{ Collinearity } \\
\hline & & & & & & & LB & $\mathbf{U P}$ & Tolerance & VIF \\
\hline (Constant) & 4.21 & .28 & 1.20 & .21 & & 5.66 & .78 & 1.62 & & \\
\hline Personal Teaching satisfaction & 4.24 & .42 & .34 & .06 & .37 & $5.57 *$ & .22 & .46 & .53 & 1.90 \\
\hline Teaching satisfaction with interpersonal relations & 4.31 & .43 & .10 & .06 & .11 & 1.59 & -.02 & .21 & .53 & 1.90 \\
\hline Teaching satisfaction with school polices & 4.01 & .56 & .07 & .04 & .10 & 1.67 & -.01 & .16 & .62 & 1.62 \\
\hline Teaching satisfaction with pay & 3.87 & .78 & .09 & .03 & .19 & $3.34 *$ & .04 & .15 & .74 & 1.34 \\
\hline Teaching satisfaction with career development & 4.12 & .61 & .12 & .04 & .19 & $3.14 *$ & .05 & .20 & .63 & 1.60 \\
\hline
\end{tabular}

\section{Discussion}

The correlation that exists in this study between perceived teacher motivation and teaching satisfaction supported the Squillini. [8] study that found a correlation between teacher motivation and teaching satisfaction. The finding by Ho and Andrew [9] that financial incentives increase productivity, corroborated this result from teaching satisfaction measurement with 202 primary and secondary school teachers. Demirtas [10] conducted a study in which one hundred teachers from nine institutes participated and confirmed the hypothesis that low salaries and reward were the most important reason that makes teachers think about leaving their job. Teaching satisfaction with career development also had positive correlation with teacher motivation in this study. The result showed that teachers thought the training affects their motivation to work which was similar with the finding of Bennell and Akyeampong [11] that in-service training in particular can increase teachers' motivation effectiveness.

The main purpose of this study was to explore the relationship between teacher motivation and teaching satisfaction, the correlation showed that teacher motivation was significantly and positively correlated with teaching satisfaction. 
It showed that when teaching satisfaction of teachers increased, they will be more motivated. In details, teacher motivation was significantly correlated with personal teaching satisfaction, teaching satisfaction with pay and teaching satisfaction with career development. Many studies have found that teacher motivation and teaching satisfaction has significant relationship, Ali and Ahmed [12] confirmed that there was strong positive effects of rewards and recognition on teacher motivation and their satisfaction, while with the findings of Muhoro and Katou [13] who pointed that teachers' performance and satisfaction can be increased if more attention is given on teachers' reward and their recognition (satisfaction, motivation, knowledge, interpersonal relations). The result truly supported the Goswami [14] study, he noted that teachers complained that their needs were not fulfilled according to their expectations, not only about the pay, there were also positively significant relation between teacher motivation and teaching satisfaction with career development. Afolabi [15] in his research with 500 teachers form 18 secondary schools in Nigeria pointed that "trained teachers were more motivated than the untrained teachers".

\section{Conclusion}

The findings of the present study have provided answers to all research question and suggest of that teachers in Islamic private secondary schools in Pattain, Thailand in general have high teacher motivation and teaching satisfaction. Teacher motivation were confirmed to have great positive significant relationship with teaching satisfaction dimensions in Islamic Private schools. The findings also suggested that the government should make a revision of the present remuneration for teachers and should propose a new incentive salary scheme and also the school managers and administrators should stress more on person orientation than task orientation when it comes to school policies formulation and implementation.

In summary, the result from hypotheses demonstrated were: there was positive significant relationship between teacher motivation and teaching satisfaction; there was influence of personal teaching satisfaction, teaching satisfaction with pay, teaching satisfaction on teacher motivation, the best predictor was personal teaching satisfaction.

\section{Recommendations}

According to the previous conclusions and discussion, the recommendations are proposed for school administrators and teachers is under the following:

a. Though, the overall level of teacher motivation and teaching satisfaction were high as reported by the results, this does not mean that the school administrators should take them for granted that teachers will always be motivated and satisfied, but they need to find effective work plan to enhance these two imperative variables. This is because teacher motivation and teaching satisfaction are considered as driving forces that push teacher to perform effectively in their profession. b. School administrators should not assume that a well-designed work is always effective, without consistently evaluating the factors that influence teacher motivation. The evaluation of these factors are crucial as they are signified as a tool for enhancement of teachers' implementation of the school work.

d. The results showed that there was no positive significant relationship between teacher motivation and teaching satisfaction with interpersonal relations and school polices. Thus the school administrator need to consider the strategies to increase the positive attitude and friendly relationship between teachers and teachers with principals in order to cooperate each other smoothly. Moreover, teachers' motivation and teaching satisfaction aspects are not homogeneous, therefore, there is a need for the school administers to use different management styles and strategies to rise to the same level of teachers' motivation and teaching satisfaction for optimum organizational effectiveness and maximize teachers' motivation.

e. It is clear that teachers are prospective for afford a very high job performance and they are the core of the education process, they have to make sure that students have gain what made of them. As a career, teachers should have professional skills and morals in teaching, so that they should motivated themselves somehow. Although they were strongly motivated by their religious belief or a higher calling, they should pay attention on teaching and school polices and environment so that they may more motivated in teaching. For teaching satisfaction, the present study showed that teachers' level of satisfaction with interpersonal relations were high but there was no significant relationship between teacher motivation and teaching satisfaction with interpersonal relations, this indicated that although teachers are satisfied with interpersonal relations, but they were recommended to make positive attitude or encourage among colleagues to motivated each other either.

f. There were three dimensions of teaching satisfaction that influence teacher motivation, namely, personal teaching satisfaction, teaching satisfaction with pay and teaching satisfaction with career development. Of these significant predictors, personal teaching satisfaction was the best predictor. Based on this result, it is recommended that the school principals/administrators and educators make strategic planning that can support the enhancement of teachers' satisfaction with respect to personal teaching satisfaction, for example, setting more activities, giving them more inspirations, making them happy to work, ensuring them the feeling of respectfulness and autonomy. The successful attaining of personal teaching satisfaction among teachers will undoubtedly influence their teaching motivation.

\section{Acknowledgements}

I would like to extend my deepest gratitude to the respectable Dr. Abudlhakam Hengpiya my supervisor, for his constant encouragement and academic guidance. Without his patience and unflinching moral support and suggesting, this 
thesis would have been impossible to complete. I have learned so much not only from his abundant knowledge but also from his admire wisdom. I would like thank Associate Professor Ibrahem Narongraksakhet and for his guiding in my paper and his kindly support, many thanks to Assistant Professor Dr. Niloh Wae-u-seng for his suggestion in my topic and orientation choosing, sincere thanks to Dr. Samsoo sa-u for his helping and guiding in the academic writing, I would like thank Associate Professor Santi Bunphirom for his and others recommendations, suggestions and generous supporting, for their insight and experience sharing. Words cannot express my gratitude for their help during my study.

\section{References}

[1] Watkins, K., 2000, The Oxfam Education Report, Oxfam Publications.

[2] Vanbaren, J. (2010), The Definition for work motivation. [Online] Available: http://www.ehow.com/facts_6951422_definition-work-motiva tion.html (June, 2012).

[3] Salehi, H., Taghavi, E., \& Yunus, M. M. (2015). Relationship between Teachers' Job Satisfaction and Their Attitudes towards Students' Beliefs and Motivation. English Language Teaching, $8(7), 46$.

[4] Skaalvik, E. M., \& Skaalvik, S. (2011). Teacher job satisfaction and motivation to leave the teaching profession: Relations with school context, feeling of belonging, and emotional exhaustion. Teaching and teacher education, 27 (6), 1029-1038.

[5] Herzberg, F., Mausner, B., \& Snyderman, B. B. (2011). The motivation to work (Vol. 1). Transaction publishers.

[6] Convey J. J. (2014). Motivation and Job Satisfaction of Catholic School Teachers. Catholic Education: A Journal of Catholic Education, 18 (1), 195-222. I. S. Jacobs and C. P. Bean, "Fine particles, thin films and exchange anisotropy," in Magnetism, vol. III, G. T. Rado and H. Suhl, Eds. New York: Academic, 1963, pp. 271-350.
[7] Ifinedo, P. (2003). Employee Motivation and Job Satisfaction in Finnish Organizations: A Study of Employees in the Oulu Region, Finland. Master of Business Administration Thesis, University of London.

[8] Squillini, C. (2001). Teacher commitment and longevity in Catholic schools. Catholic Education, A Journal of Inquiry and Practice, 4, 335-354.

[9] Andrew, J. (2001) "Approach and Avoidance Motivation". Educational Psychology Review 13 (2001): 2.

[10] Demirtas, Z. (2010). Teachers' job satisfaction levels. Procedia-Social and Behavioral Sciences, 9, 1069-1073. Salehi, H., Taghavi, E., \& Yunus, M. M. (2015). Relationship between Teachers' Job Satisfaction and Their Attitudes towards Students' Beliefs and Motivation. English Language Teaching, $8(7), 46$.

[11] Bennell. P. and Akyeampong, K. (2007) Teacher Motivation in Sub-Saharan Africa and South Asia. Researching the Issues 71, Department for International Development: Education Papers, 2007.

[12] Ali \& Ahmad, K. B. (2015). Educational practice: lessons to be learned from madrasah and religious schools in contemporary Southeast Asia. Indonesian Journal of Islam and Muslim Societies, 5 (1), 29-48.

[13] Muhoro, N. M. (2013). Influence of Headteachers' Motivational Practices On Job Satisfaction of Public Primary School Teachers In Gatanga District, Murang'a County, Kenya (Doctoral dissertation, University of Nairobi).

[14] Goswami, S. (2015). Education in India at a glance: Pre-primary to Higher Education. Future of education and society through the eyes of social researchers, 26-87.

[15] Afolabi, C. Y. (2012) The Influence of Gender, Age, Training and Experience on Teachers' Motivation in Ado and Efon Local Government Areas, Ekiti State, Nigeria. Greeener Journal Educational Research. ISSN: 2276-7789 Vol. 3 (3), pp. 138-143. 